\title{
CD151-mediated adhesion is crucial to osteosarcoma pulmonary metastasis
}

\author{
Zhuoying Wang ${ }^{1, *}$, Chongren Wang ${ }^{1, *}$, Zifei Zhou ${ }^{1, *}$, Mengxiong Sun ${ }^{1}$, Chenghao \\ Zhou $^{2}$, Jian Chen ${ }^{2}$, Fei Yin ${ }^{2}$, Hongsheng Wang ${ }^{2}$, Binhui Lin ${ }^{1}$, Dongqing Zuo ${ }^{2}$, \\ Suoyuan Li ${ }^{2}$, Lijin Feng ${ }^{3}$, Zhenfeng Duan' ${ }^{4}$ Zhengdong Cai ${ }^{1,2}$, Yingqi Hua ${ }^{1,2}$

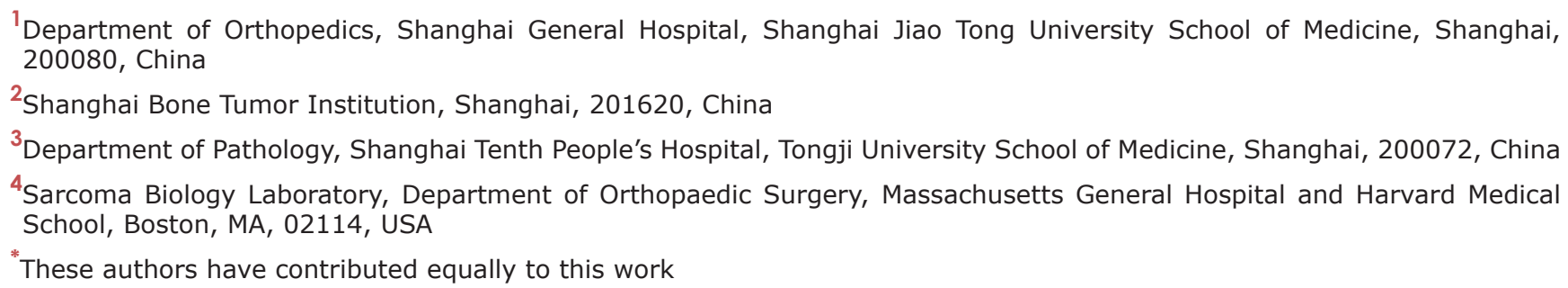

Correspondence to: Zhengdong Cai, email: czd856@vip.163.com Yingqi Hua, email: hua_yingqi@163.com

Keywords: osteosarcoma, tetraspanin, CD 151, metastasis, adhesion

Received: December 25, $2015 \quad$ Accepted: July 26, $2016 \quad$ Published: August 19, 2016

\section{ABSTRACT}

CD151, a tetraspanin family protein involved in cell-cell and cell-extracellular matrix interaction, is differentially expressed in osteosarcoma cell membranes. Thus, this study aimed to investigate the role of CD151 in osteosarcoma metastasis. We analyzed CD151 expression in patient tissue samples using immunohistochemistry. CD151 expression was also silenced with shRNA in osteosarcoma cells of high metastatic potential, and cell adhesion, migration and invasion were evaluated in vitro and pulmonary metastasis was investigated in vivo. Mediators of cell signaling pathways were also examined following suppression of CD151 expression. Overall survival for patients with low versus high CD151 expression level was 94 vs. 41 months $(p=0.0451)$. CD151 expression in osteosarcoma cells with high metastatic potential was significantly higher than in those with low metastatic potential $(p<0.001)$. shRNA-mediated silencing of CD151 did not influence cell viability or proliferation; however, cell adhesion, migration and invasion were all inhibited (all $p<0.001)$. In mice inoculated with shRNA-transduced osteosarcoma cells, the number and size of lung metastatic lesions were reduced compared to the mice inoculated with control-shRNA transduced cells $(p<0.001)$. In addition, CD151 knockdown significantly reduced Akt, p38, and p65 phosphorylation as well as focal adhesion kinase, integrin $\beta 1$, p70s6, and p-mTOR levels. Taken together, CD151 induced osteosarcoma metastasis likely by regulating cell function through adhesion signaling. Further studies are necessary to fully explore the diagnostic and prognostic value of determining CD151 expression in osteosarcoma patients.

\section{INTRODUCTION}

Osteosarcoma is the most common primary bone tumor in adults and the third most common solid tumor in pediatrics with a 5-year survival rate of 60$70 \%$ [1]. However, a recent multicenter study analyzing osteosarcoma in Asian adults $>40$ y revealed that nearly
$11 \%$ presented with initial metastasis, and response to neoadjuvant chemotherapy was classified as poor in $73 \%$ of those receiving it [2]. Patients with metastasis are less sensitive to chemotherapy with 5-year survival rate of $20-40 \%$ [1]. It is important to investigate mechanism underlying osteosarcoma metastasis and develop treatment strategy afterward. 
The transmembrane protein, CD151, is a member of the transmembrane 4 superfamily, which consist of two extracellular domains, an intracellular $\mathrm{N}$ terminus, a loop and a C terminus $[3,4]$. CD151 forms tetraspaninenriched microdomains (TEMs) and may act on growth factor receptors and the laminin receptor, integrin, via its extracellular domain. It also interacts with intracellular signaling molecules, including phosphatidylinositol-4-OH kinase (PI4K), protein kinase $\mathrm{C}$ (PKC) and cytoskeleton proteins, through its intracellular domain, mediating cell-to-cell interactions or cell-to-extracellular matrix interactions. CD151 is closely related to the progression of breast, prostate and colon cancer, promoting metastasis [5-11]. In prostate cancer cells, CD151 is associated with increased invasiveness and lymphangiogenesis [12]. In addition to CD151 being a putative diagnostic and prognostic marker, its value as a therapeutic target has been shown in studies of CD151-specific antibodies [13]. Specifically, a monoclonal antibody, mAb 1A5, that targets CD151 inhibited fibrosarcoma and squamous cell skin cancer metastasis in vivo $[14,15]$. Other antibodies against CD151, including 50-6, SFA1.2B4 and 1A5, significantly inhibit metastasis through suppression of angiogenesis, cell migration and invasion as well as intravascular permeability [4, 15-17].

We have previously shown that CD151 was highly expressed on the membrane of MG-63 osteosarcoma cells as compared to human hFOB1.19 osteoblastic cells [18]. To further investigate its role in osteosarcoma metastasis, CD151 expression was evaluated in paired osteosarcoma cells with high (LM8 and MG63.2 cells) and low (Dunn and MG63 cells) metastatic potentials. In addition, CD151 expression was silenced in osteosarcoma cells with high metastatic potential ( $\triangle$ CD151 cells), and the adhesion, migration and invasion of these cells were subsequently evaluated. $\triangle \mathrm{CD} 151$ cells were also inoculated into the primary osteosarcoma orthotopic model, and the pulmonary metastasis was assessed along with the mechanism underlying osteosarcoma metastasis. This study aimed to confirm the positive relationship between osteosarcoma metastasis and CD151 expression, and to examine the role of CD151 on osteosarcoma cell migration and invasion.

\section{RESULTS}

\section{CD151 expression in human osteosarcoma is conversely associated with patient survival}

To evaluate the clinical significance of CD151 expression in human osteosarcoma, IHC analyses were conducted in two independent tumor tissue microarrays. TMA 1 consists 39 patients of which the demographic data and clinical characteristics of all patients are listed in Table 1. Of the osteosarcoma patients analyzed, 21 did not have metastases while 18 patients had metastasis.
CD151 was only weakly expressed in the normal human muscle tissue (data not shown). In contrast, CD151 immunoreactivity was detected in a wide range of intensities in osteosarcoma tissue samples (Figure 1A). The median immunoreactive score (IRS) for CD151 expression in the 21 patients without metastasis was 6.0 (IQR in 4.5-12.0), and was 8.3 (IQR in 5.8-10.0) in the 18 patients with metastasis; however, the difference did not reach a statistical significance $(p=0.757$, Figure $1 \mathrm{~B})$.

In TMA 2, containing a larger patient cohort and longer follow-up time, we found that the overall survival of patients with low CD151-expressing tumors (levels $1-8.9, \mathrm{n}=54$ ) was significantly higher than those with high-expressing tumors (levels 9-12, $\mathrm{n}=55)(p=0.0451)$ with median survival times of 94 months and 41 months, respectively (Figure 1C). In addition, the 10-year survival rate was $47.05 \%$ in the low-level group versus $34.49 \%$ in the high-level group.

\section{CD151 expression is associated with the metastatic potential of osteosarcoma cell lines}

The murine LM8 osteosarcoma cell line, a derivative the Dunn cell line, has higher metastatic potential than Dunn cells [19]. Flow cytometry analysis revealed that the proportion of cells with CD151 surface expression was $78.1 \pm 0.95 \%$ in LM8 cells, which was significantly higher than $13.6 \pm 0.4 \%$ in Dunn cells $(\mathrm{P}<0.001)$ (Figure $2 \mathrm{~A}$ ). Western blot analysis also confirmed that total CD151 expression was significantly higher in LM8 cells than that in Dunn cells (Figure 2B). Similarly, human MG63.2 cells, a derivative of MG63 cells with a higher metastatic potential [20], had significantly higher CD151 expression than MG63 cells $(p<0.001)$ (Figure 2B). These findings suggested that CD151 expression is increased in cells with high metastatic potential.

Because LM8 and MG63.2 displayed significantly higher expression of CD151, these cell lines were selected as our representative models for subsequent functional analyses. Both osteosarcoma cell lines were transduced with sh-CD151-expressing lentiviral vectors (KD1 and KD2) or with the empty lentiviral vector (vector control). Compared with vector control group, CD151 expression in LM8 and MG63.2 cells was reduced by $87.5 \%$ (1.92 in vector vs. 0.27 in $\mathrm{KD} 1$ and 0.21 in KD2, $p<0.001)$ and $72.5 \%$ (1.2 in vector vs. 0.33 in KD1 and 0.32 in KD2, $p<0.001$ ) (Figure 2C). Thus, $\Delta$ CD151 LM8 and MG63.2 cells were successfully established.

\section{CD151 did not alter osteosarcoma cell viability, cell cycle progression, and apoptosis}

To investigate the biological function of CD151 in osteosarcoma, we next evaluated the viability, cell cycle progression, and apoptotic rates of the various $\triangle \mathrm{CD} 151$ LM8 and MG63.2 cells. As shown in Figure 3A, CD151 
A
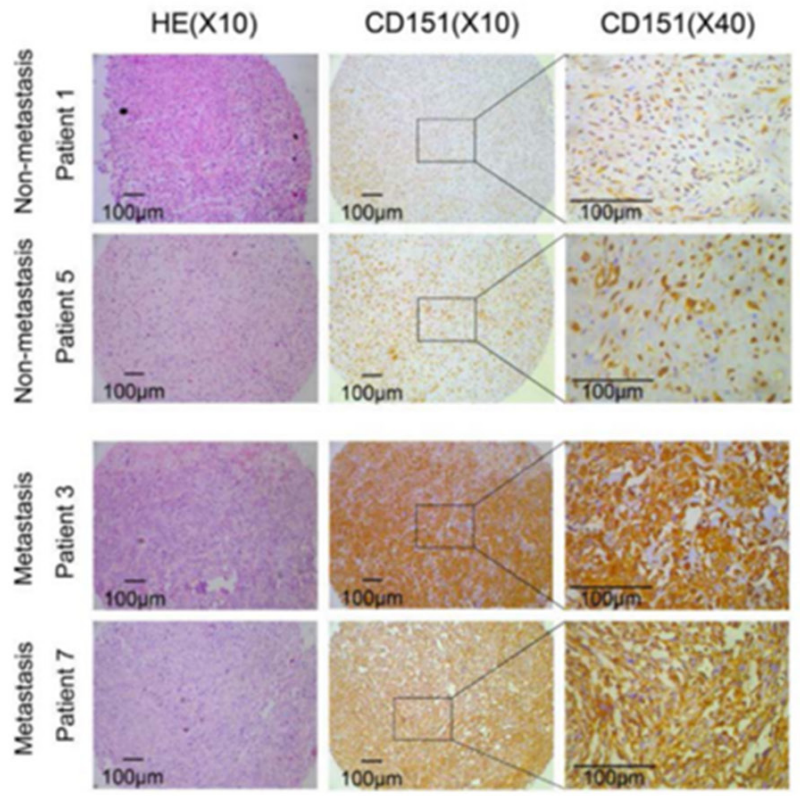

B

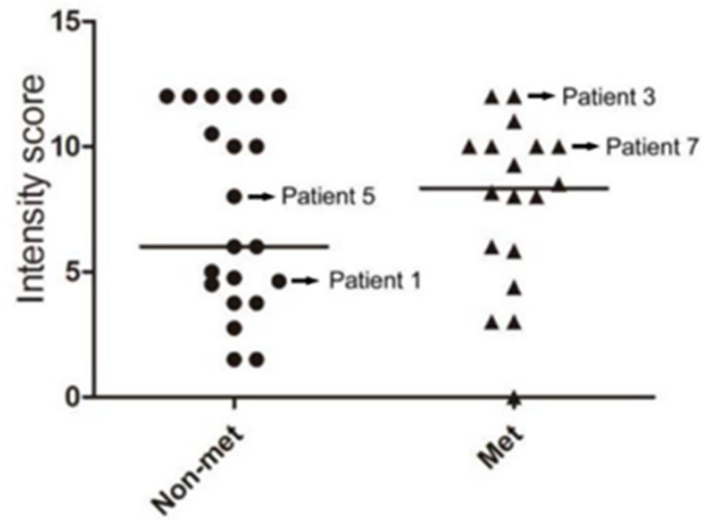

$\mathrm{C}$

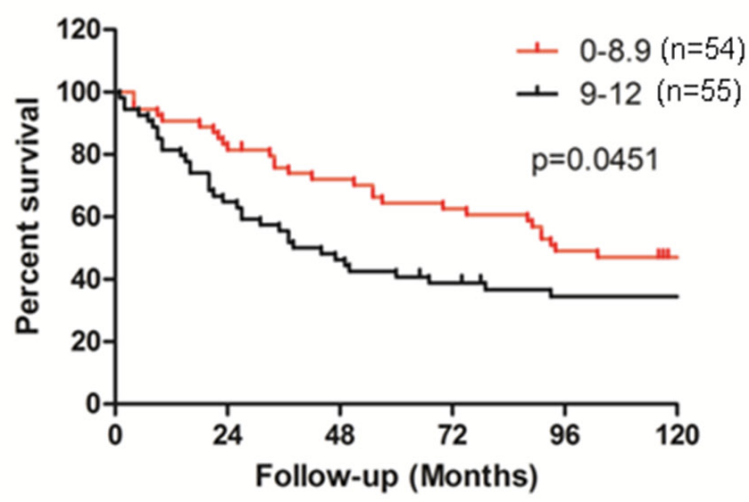

Figure 1: CD151 protein expression in human osteosarcoma. A. Representative images from the immunohistochemical analysis of CD151 protein levels in tumor samples. B. Comparison of CD151 immunoreactivity in osteosarcoma tissues from non-metastatic patients and metastatic patients. Dash lines in the figure show the median values. C. Kaplan-Meier curves with log-rank tests were performed to investigate the differences of survival rate between patients with low $(1-8.9 ; \mathrm{n}=54)$ and high $(9-12 ; \mathrm{n}=55) \mathrm{CD} 151$ levels $(p=0.0451)$. 
Gender

Male

$23(59.0 \%)$

Female

$16(41.0 \%)$

Tumor metastasis

Non-metastasis

$21(53.8 \%)$

Metastasis

$18(46.2 \%) *$

Primary site

Ilium

$5(12.8 \%)$

Humerus

4 (10.3\%)

Femur

$18(46.2 \%)$

Tibia

$8(20.5 \%)$

Others

$4(10.3 \%)$

Score

$\leq 5 \quad 13(33.3 \%)$

$5-10$

$10(25.6 \%)$

$\geq 10$

$16(41.0 \%)$

*There were 14 lung metastases.

silencing did not alter cell viability at 24 and $72 \mathrm{~h}$. Analysis of the cell cycle distribution by flow cytometry revealed that the proportions of KD1 and KD2-expressing LM8 and MG63.2 cells in sub-G1, G0/G1, S and G2/M phases show no difference to that observed for the vector control cells (Figure 3B). Similar results were obtained for KD1, KD2 and vector-expressing LM8 and MG63.2 cells cultured in 3D (Figure 3B). The proportion of apoptotic cells in each cell type is shown in Figure 3C. In both adherent cells and suspended cells, the proportion of apoptotic cells remained unchanged after CD151 knockdown. Thus, suppression of CD151 expression did not affect osteosarcoma cell viability, cell cycle progression or apoptosis.

\section{CD151 silencing reduces osteosarcoma cell-cell attachment and adhesion}

CD151 is a cell membrane molecular related to adhesion, which is important for cancer cell motility. In order to test its role in osteosarcoma, we next studied whether CD151 silencing reduced the cell-cell attachment or cell adhesion of osteosarcoma cells. Analysis of the cellcell attachment spheroid area as determined by Image $\mathrm{J}$ showed that cell-cell attachment was significantly reduced in the KD1 and KD2-expressing LM8 and MG63.2 cells at 24,48 , and $72 \mathrm{~h}$ as compared to the vector control cells ( $p \leq 0.001$; Figure 4A). As shown in Figure 4B, LM8 and
MG63.2 osteosarcoma cell adhesion following CD151 knockdown was significantly reduced compared with vector control cells $(p<0.001)$.

\section{Suppression of CD151 expression reduced osteosarcoma cell migration and invasion}

To further validation the relation between CD151 and cell motility, the effect of CD151 suppression on osteosarcoma cell migration and invasion was next examined. As shown in Figure $5 \mathrm{~A}$ and $5 \mathrm{~B}$, the migration rate was significantly lower in both KD1 and KD2expressing LM8 and MG63.2 cells at $48 \mathrm{~h}$ compared to the vector control (all $p<0.001$ ). Similarly, the number of invaded CD151-KD1 and CD151-KD2 cells was significantly reduced compared with the vector control group ( $p<0.001$; Figure 5C, 5D).

\section{CD151 silencing alters osteosarcoma cell signaling}

Because CD151 interaction with extracellular matrix or intercellular junctions can alter the migration of malignant cells through cell signaling [13], the effects of its suppression on cell signaling molecules with known roles in cell motility and migration, including the Akt and p38 signaling pathways $[21,22]$, were detected by 
A
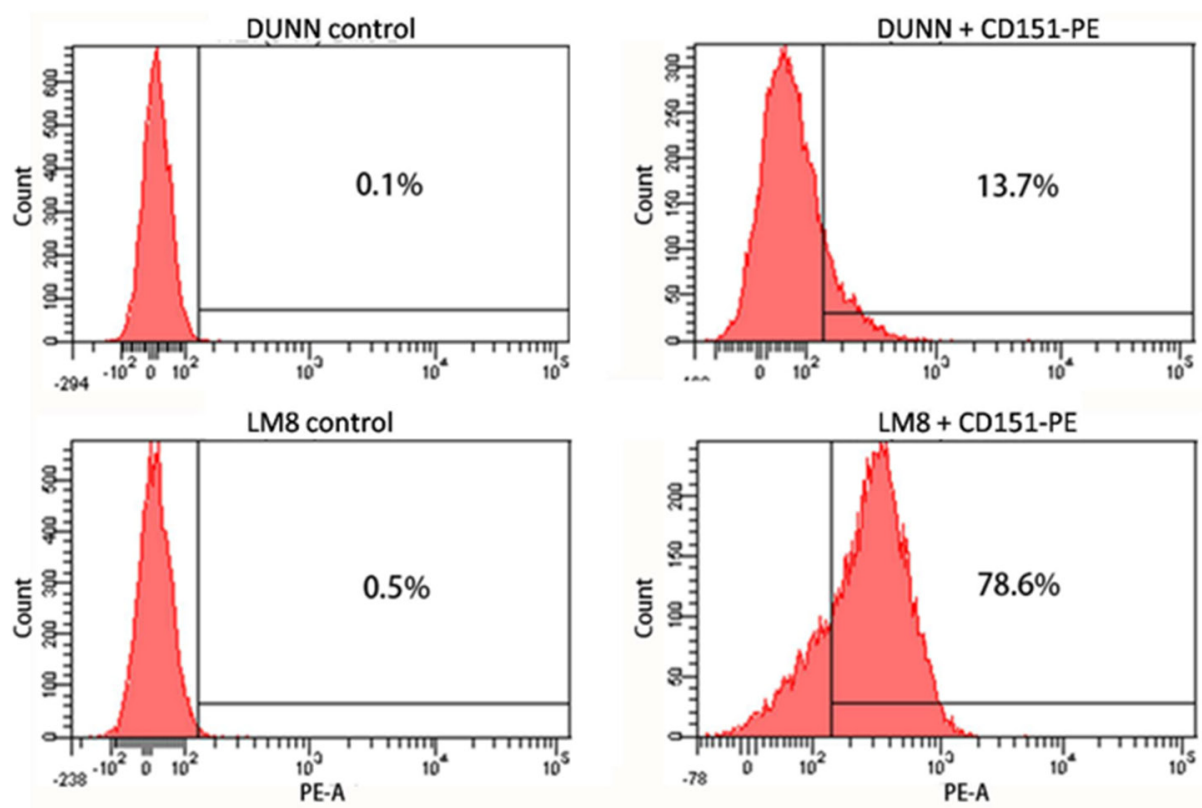

B
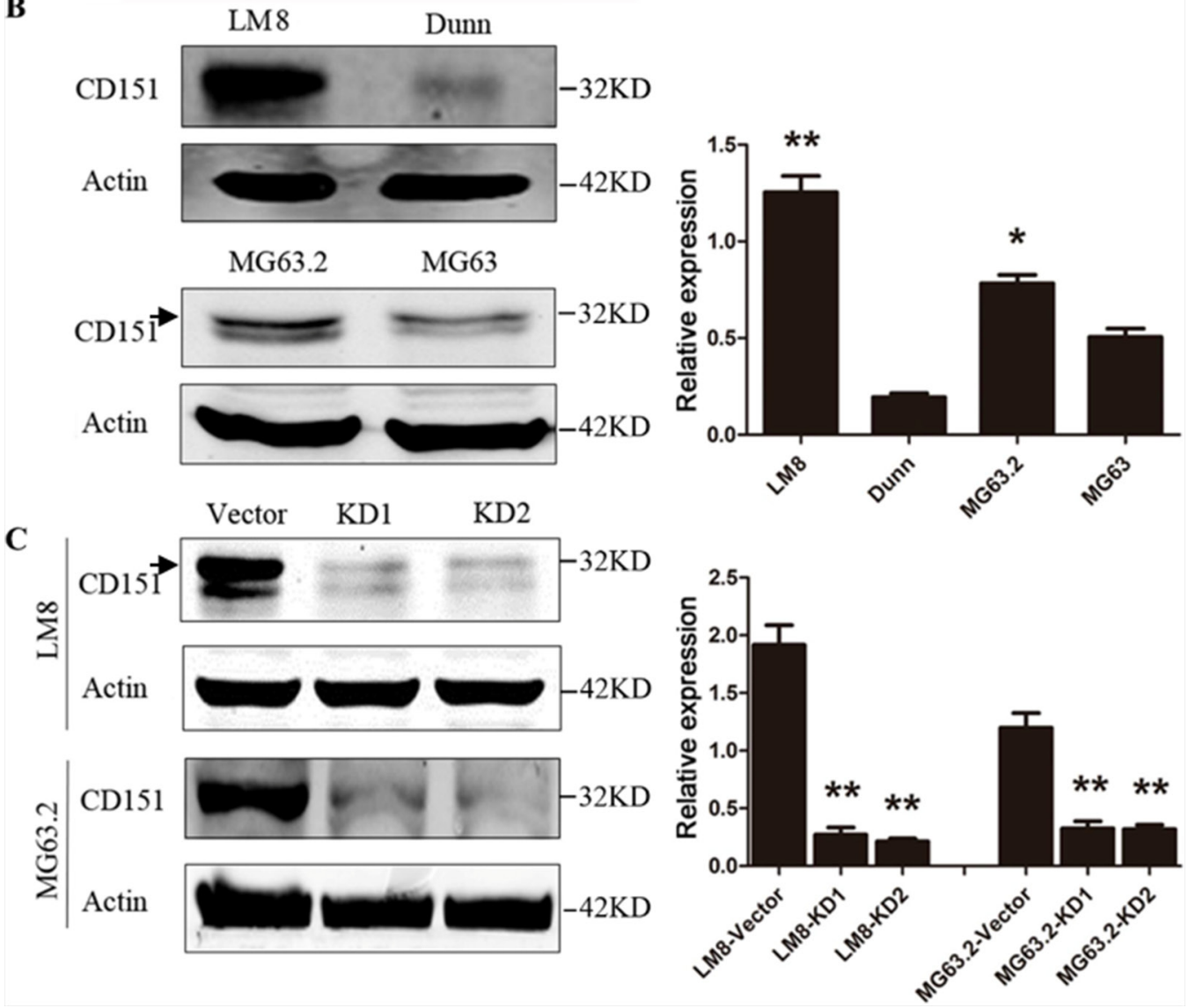

Figure 2: CD151 protein expression in osteosarcoma cell lines. A. Detection of CD151 expression on the membranes of osteosarcoma cell lines, Dunn and LM8 cells, as determined by flow cytometry. B. Detection of CD151 expression in the osteosarcoma cell lines, LM8, Dunn, MG63, and MG63.2) by Western blot analysis. *LM8 and MG63.2 cells had significantly higher CD151 expression than Dunn and MG63 cells $(p<0.001)$. C. LM8 and MG63.2 osteosarcoma cell were transduced with lentiviral vectors to express shRNA sequences targeting CD151 transcript (KD1 and KD2) or with empty lentiviral vectors (vector control). The expression of CD151 was determined by Western blotting. *Compared with vector control group, CD151 expression in LM8 and MG63.2 cells was significantly reduced (all $p<0.001$ ). Quantitative data are presented by mean and SD of three independent experiments. An arrow indicates the main band of CD151 in Western blot analysis. 
A

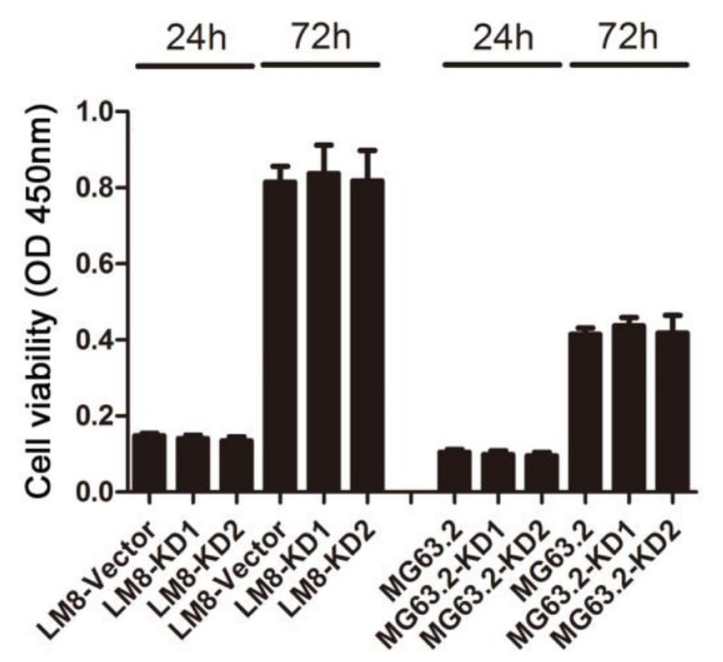

B
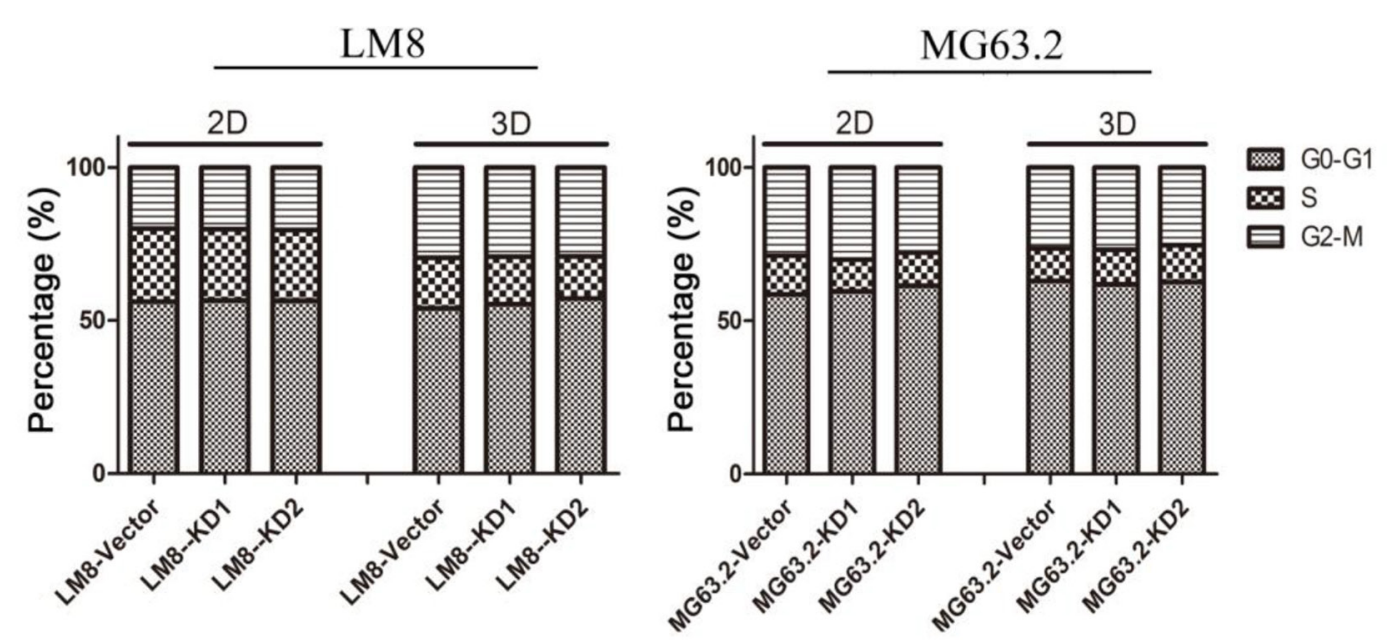

C
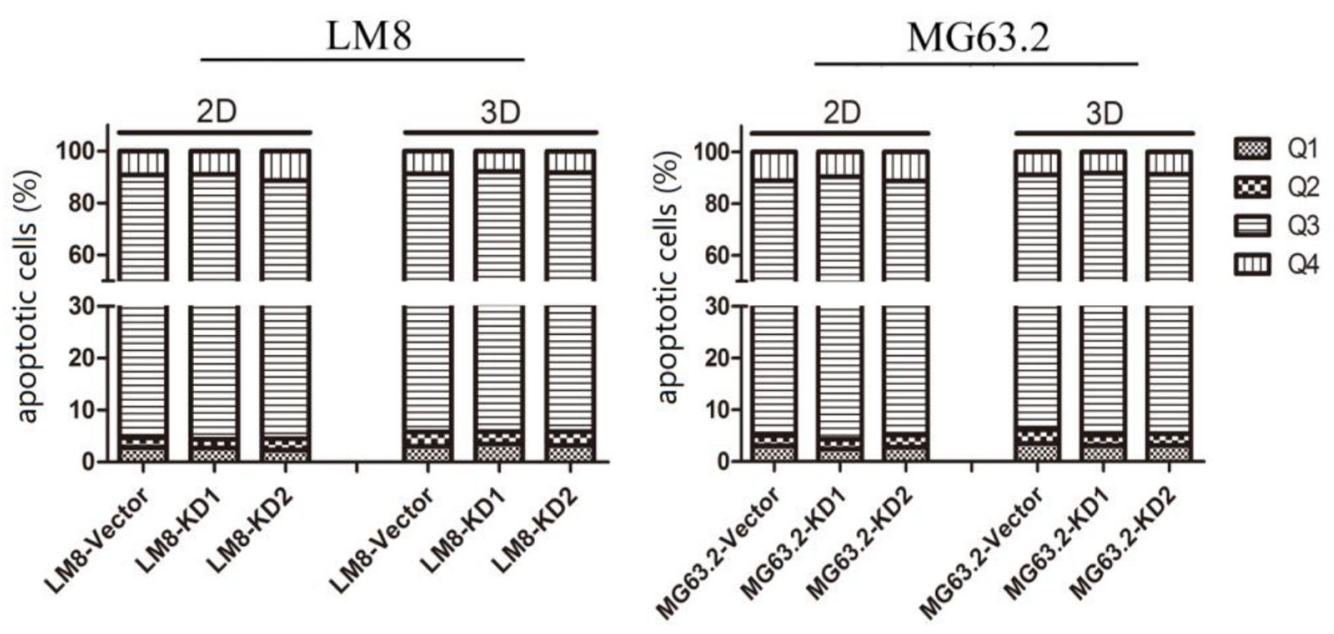

Figure 3: Effects of CD151 knockdown on LM8 and MG63.2 cell viability, cell cycle progression and apoptosis. A. Cell viability was assessed in vector, KD1 or KD2 cells by MTT assays at 24 and $72 \mathrm{~h}$ after the cells were seeded in 96-well culture dishes using flow cytometry. B, C. Cells were seeded in normal (2D) 6-well culture dishes and three-dimensional (3D) 6-well culture dishes. After 24 $\mathrm{h}$, cells were harvested for analysis of (B) cell cycle progression or (C) apoptosis. Each bar represents the mean value and the SD value (standard deviation) of five wells. Quadrant 1 (Q1) represents necrotic cells, quadrant 2 (Q2) late apoptotic cells, quadrant 3 (Q3) intact cells, and quadrant 4 (Q4) early apoptotic cells. 
A
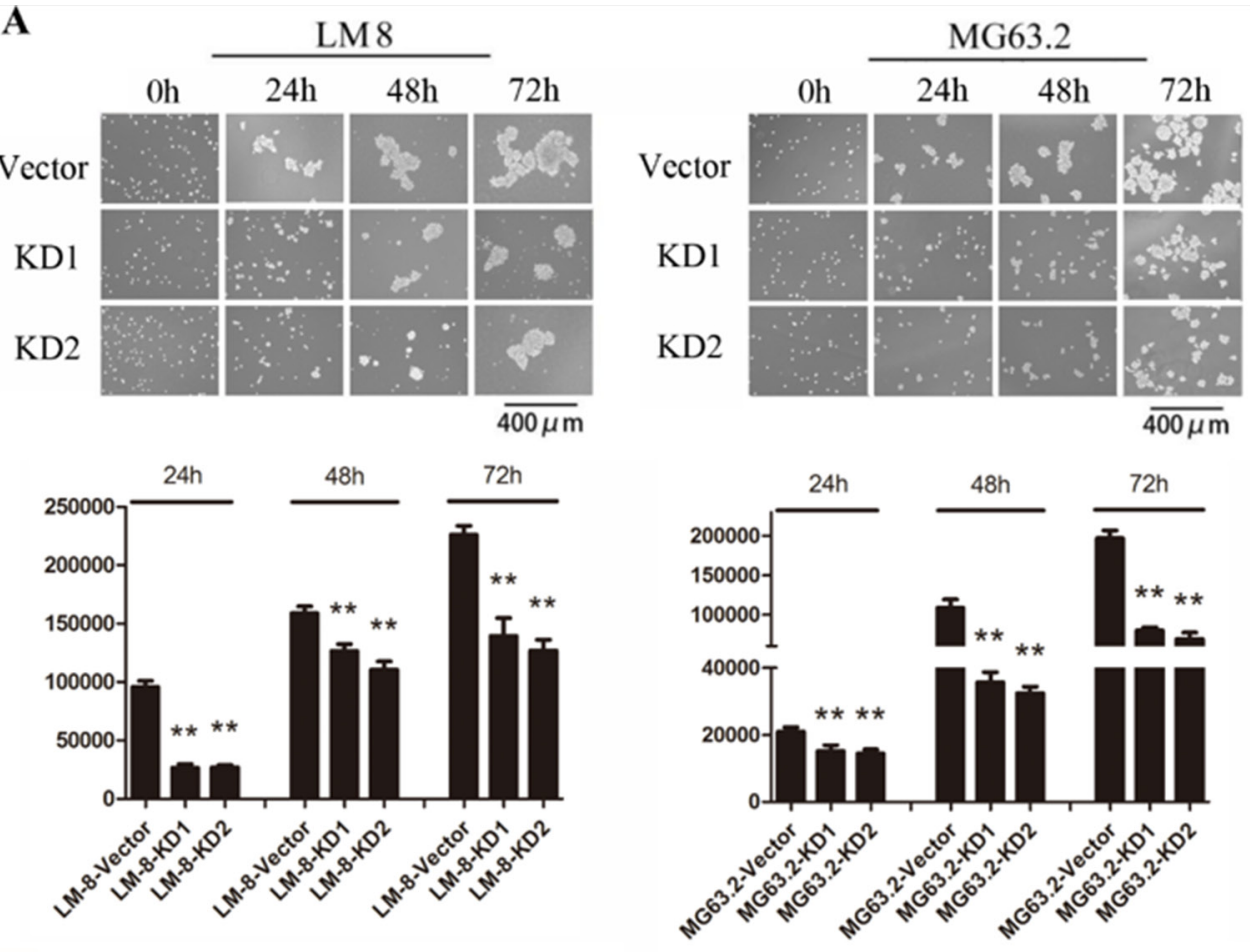

B
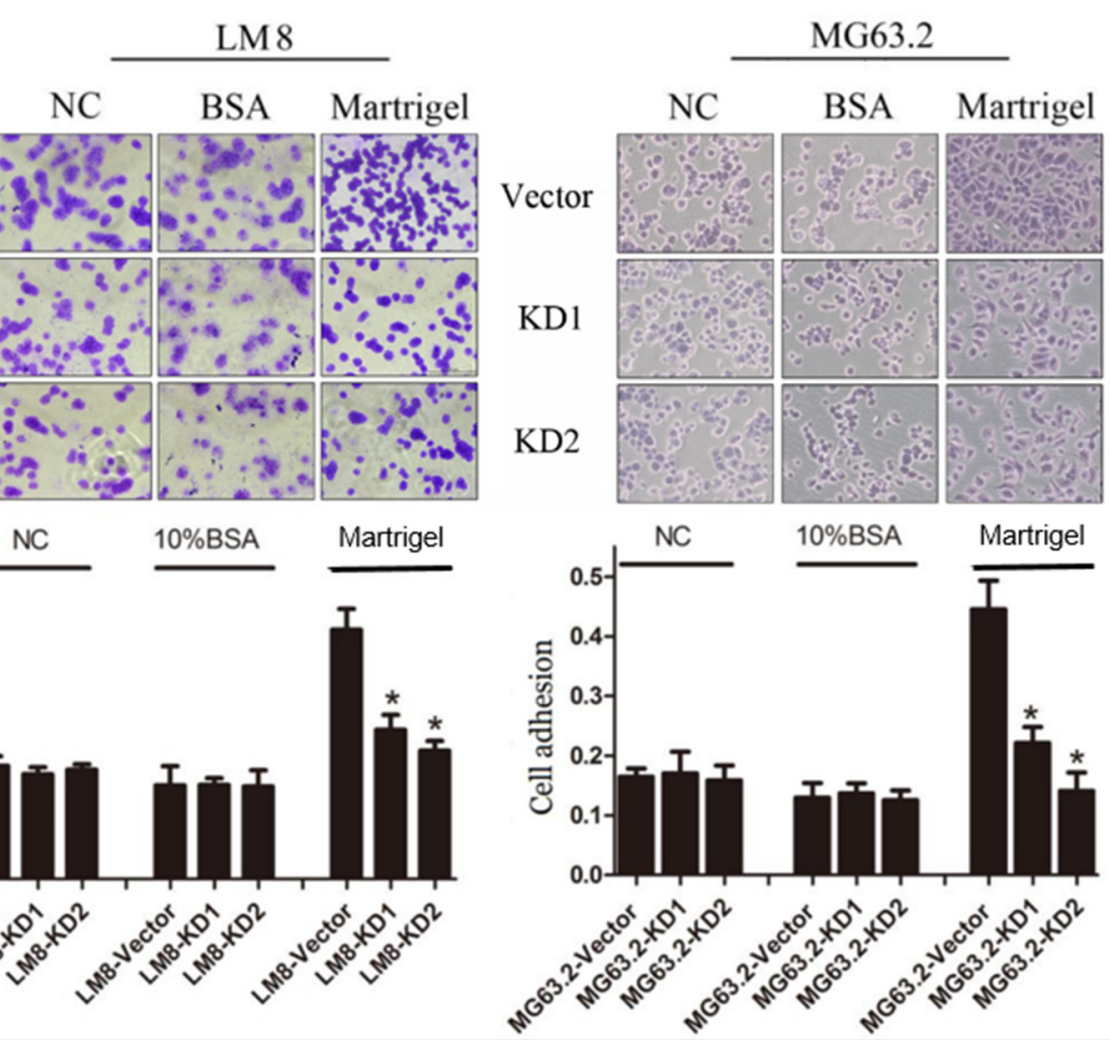

Figure 4: Effects of CD151 knockdown on osteosarcoma cell-cell attachment and cell adhesion. A. Representative images of cell-cell attachment were shown for cells expressing the control or CD151 shRNA after 0, 24, 48 and $72 \mathrm{~h}$ of Poly-HEMA-coated nonadherent three-dimensional culture. Average colony areas in multiple random fields were quantified. B. Equal numbers of the indicated cells were seeded in 96-well plates precoated with Matrigel, BSA or nothing for $45 \mathrm{~min}$. The attached cells were fixed with $95 \%$ ethanol, stained with crystal violet, and visualized using a phase-contrast microscope. Scale bar: $100 \mu \mathrm{m}$. Absorbance was measured at $595 \mathrm{~nm}$ after the crystal violet was dissolved with $33 \%$ glacial acetic. Quantitative data are presented by mean and SD of three independent experiments. " $p<0.01$, indicates a statistically significant difference compared to the vector control. 
western blot. Protein levels of Akt, phosphorylated Akt (p-Akt), p38, phosphorylated p38 (p-p38), focal adhesion kinase (FAK), CD29 (integrin $\beta 1$ ), p70s6, p-mTOR, p-p65, and p65 were analyzed. In LM8 cells, CD151 knockdown reduced Akt phosphorylation; both Akt and p-Akt levels were decreased in MG63.2 cells following CD151 knockdown. In addition, p38 phosphorylation in LM8 and MG63.2 cells were both reduced with CD151 knockdown. CD151 knockdown also reduced FAK, CD29, p70s6, p-mTOR, p-p65 and p65 expression in both LM8 and MG63.2 cells (Figure 6).

\section{Depletion of CD151 attenuates pulmonary metastasis in vivo}

We next investigated whether CD151 ablation attenuated pulmonary metastasis in vivo using an orthotopic osteosarcoma tibial model with pulmonary metastasis model. As shown in Figure 7A, there was no significant difference in the primary tumor weights among the groups in mice either inoculated with LM8 cells or MG63.2 cells. However, the lung weights of mice inoculated with KD1 and KD2-expressing LM8 and MG63.2 cells were significantly reduced as compared to the vector control group (all $p<0.001$; Figure 7B).

Representative photographs of the pulmonary metastatic foci were shown in Figure 7C, and representative lung $\mathrm{HE}$ images of the metastases were shown in Figure 7D. Analysis of the number of metastatic foci in the lungs revealed that there were fewer in mice inoculated with CD151-KD1 and CD151-KD2 expressing LM8 and MG63.2 cells compared with those inoculated with control cells (all $p<0.001$; Figure 7E), suggesting that CD151 expression contributes to the progression of pulmonary metastasis.

\section{DISCUSSION}

CD151 expression is closely related to the progression of breast, prostate and colon cancer [5-10]; its expression is positively associated with the metastasis of breast [8, 23-25] and prostate [5, 11, 26] cancers. However, its role in osteosarcoma was relatively unknown. This study presents clinical and experimental evidence
A

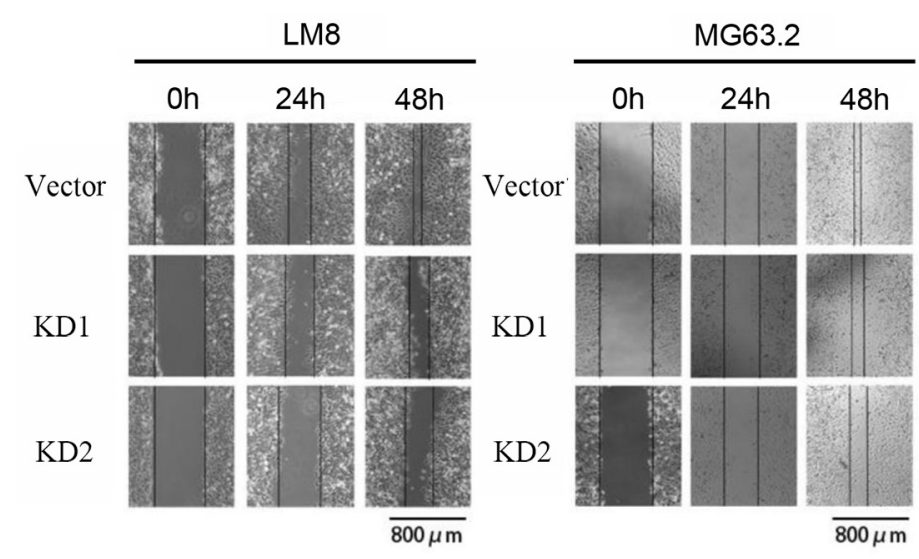

C

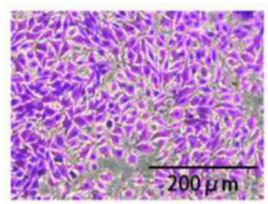

LM8-Vector

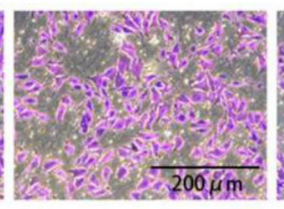

LM8-KD1

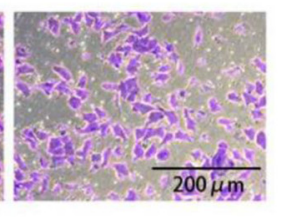

LM8-KD2
B

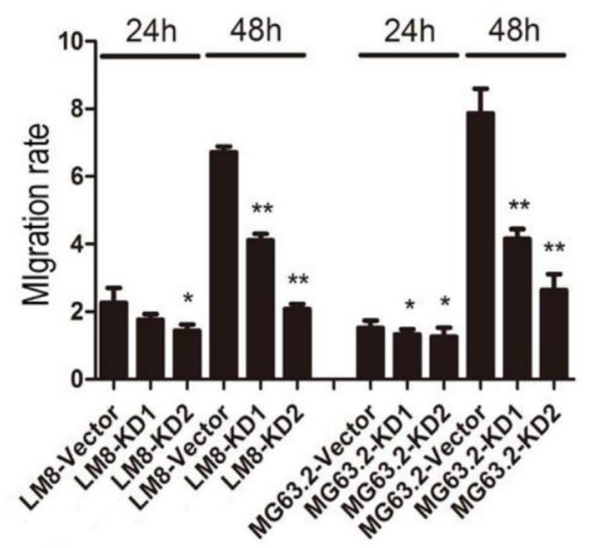

D

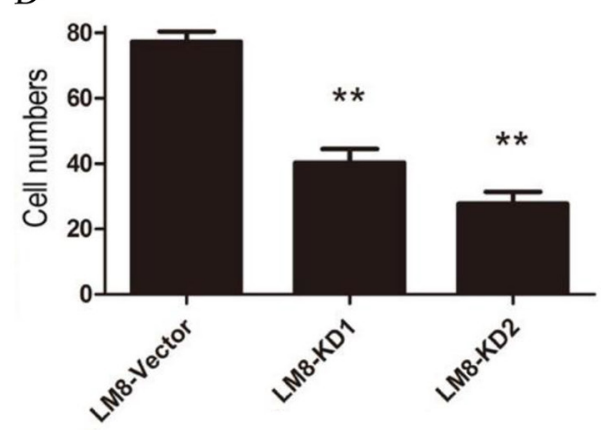

Figure 5: CD151 knockdown inhibits osteosarcoma cell migration and invasion. A. Representative images of LM8 and MG63.2 cell migration. B. The migration rate was determined by measuring the mean change in the gap width at three representative sites. Quantitative data are presented by mean and SD of three independent experiments. C. Representative images of Matrigel invasion by LM8 cells. D. Comparison of invaded cell numbers among groups. *indicates a statistically significant difference compared to the vector control (all $p<0.001)$. ${ }^{*}$ indicates a statistically significant difference compared to the KD1 group ( $p<0.001$ for LM8 cells and $p=0.013$ for MG63.2 cells). 
of the role of CD151 in osteosarcoma metastasis. In the present study, IHC analysis revealed that patients with metastasis had greater CD151 expression as compared to those without metastasis although the difference was not significant. Consistent with this observation, CD151 knockdown markedly reduces osteosarcoma cell migration and invasion, but not cell viability, cell cycle progression or apoptosis. Furthermore, cell-cell attachment and adhesion in osteosarcoma cells were markedly decreased with CD151 knockdown as was the phosphorylation of p38 and Akt and the expression levels of FAK and integrin $\beta 1$. Finally, an in vivo pulmonary metastasis model revealed that inoculation of shCD151-expressing osteosarcoma cells, which are originally highly metastatic, produced few lung metastases as compared to the vector control cells. Taken together, our results demonstrate that CD151 knockdown attenuates osteosarcoma tumor pulmonary metastasis and points to a new role for CD151 as a regulator of cell adhesion between tumor cells and the extracellular matrix.

Previous datasets by Kobayashi, Guenther, and Buddingh (http://hgserver1.amc.nl/cgi-bin/r2/main. cgi? \&species=hs) have suggested a positive correlation between CD151 expression and tumor metastasis (Supplementary Figure 1). In addition to its role in cancer progression and metastasis, studies have shown that CD151 promotes tumor neovascularization [13] and tumor growth [4]. Furthermore, elevated CD151 expression was previously linked to poor prognosis in human lung [27] and prostate cancers [5]. Furthermore, our previous work has suggested that CD151 may represent a new biomarker in the detection and diagnosis of human osteosarcoma [18]. In the present study, slightly higher but not significant expression level of CD151 was detected

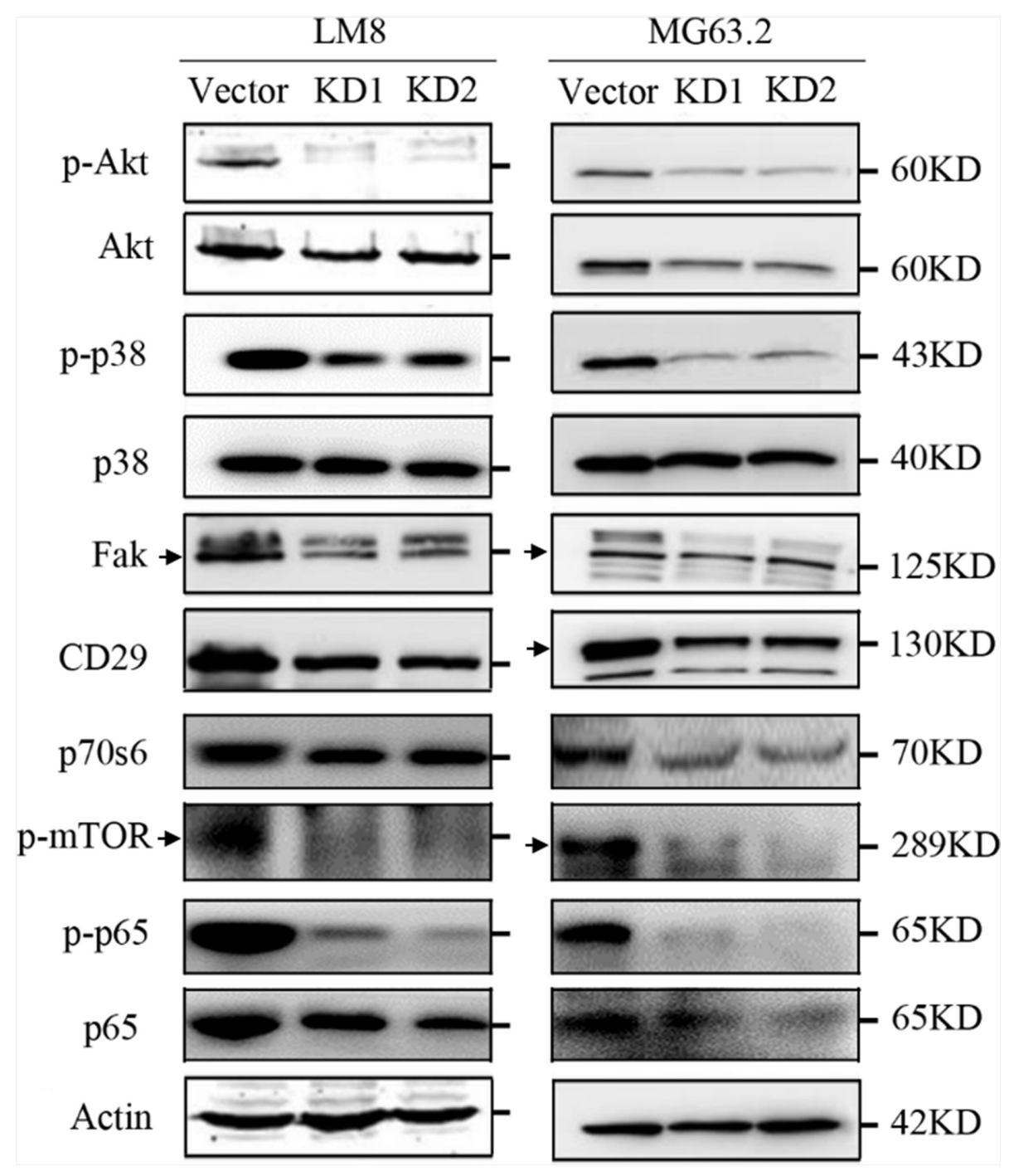

Figure 6: CD151 silencing alters osteosarcoma cell signaling. Phosphorylated versus total protein ratios of Akt, p38, and p65 as well as FAK, CD29, p70s6, and p-mTOR levels in LM8 and MG63.2 were determined by Western blot analysis. An arrow indicates the main band of each molecule in Western blot analysis. 
A

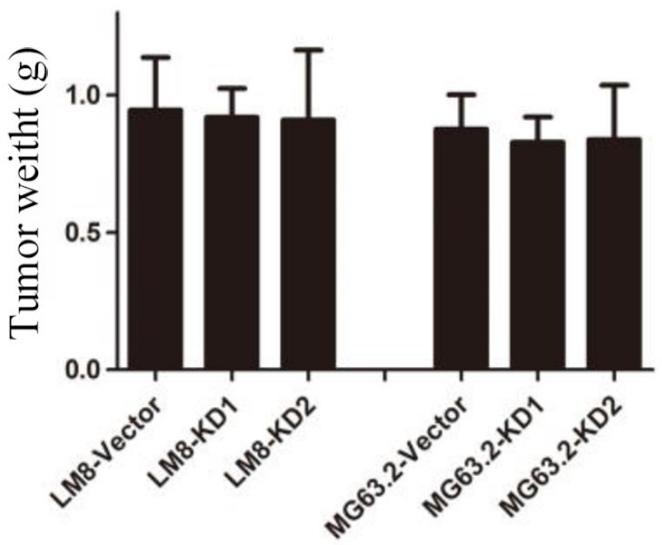

C

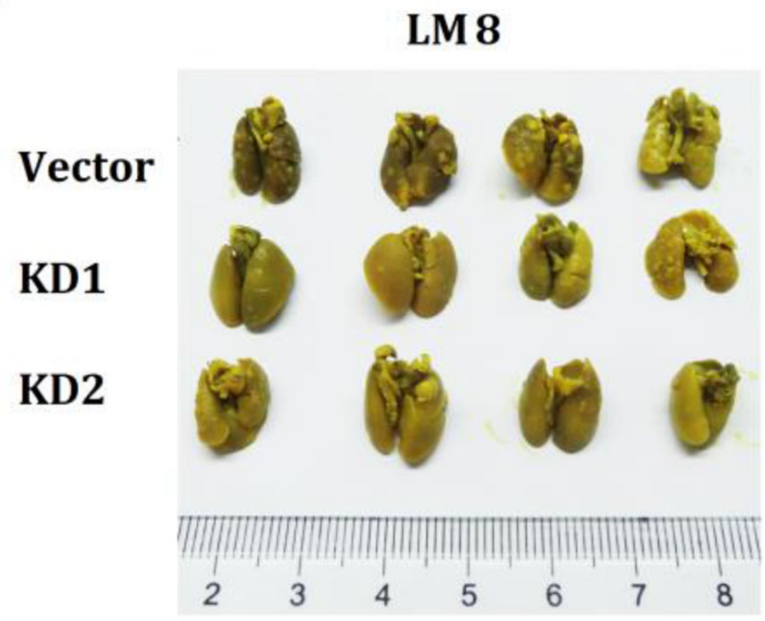

D
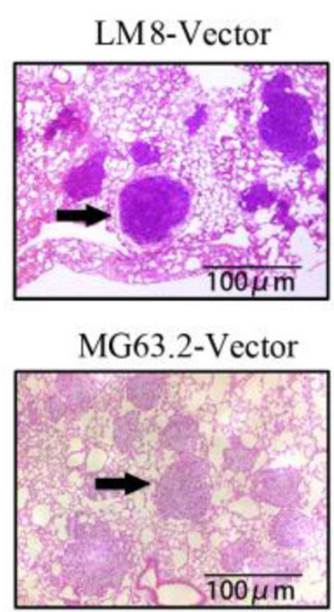

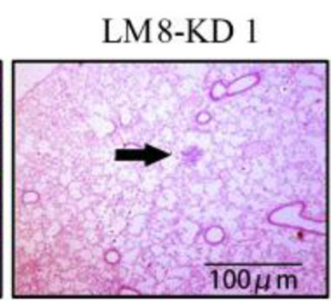

MG63.2-KD 1

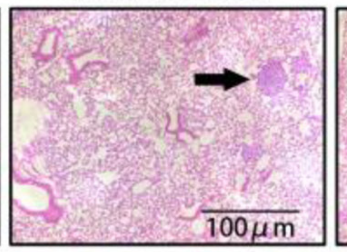

LM8-KD 2

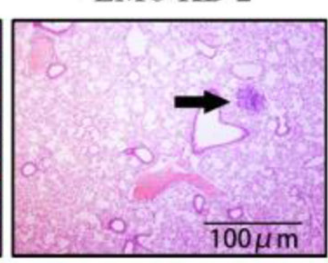

MG63.2-KD 2

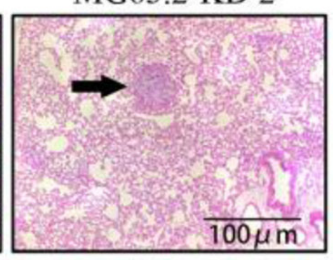

B

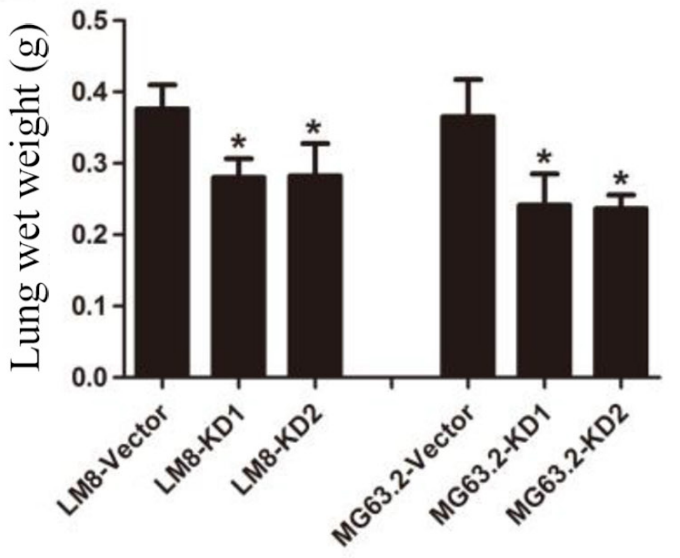

MG63.2

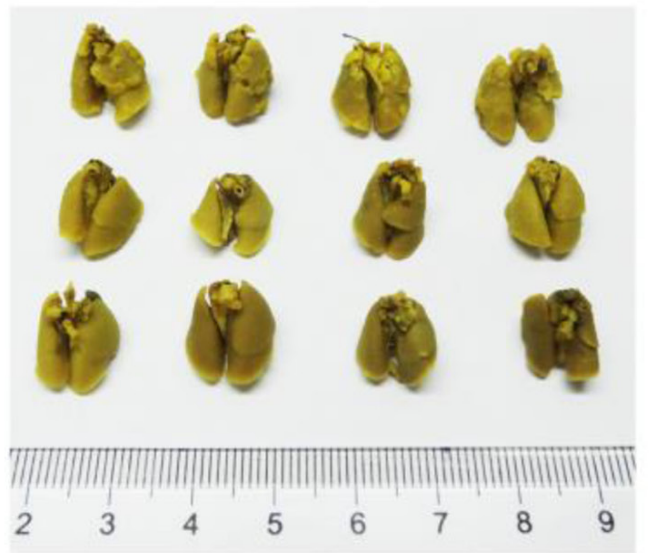

E

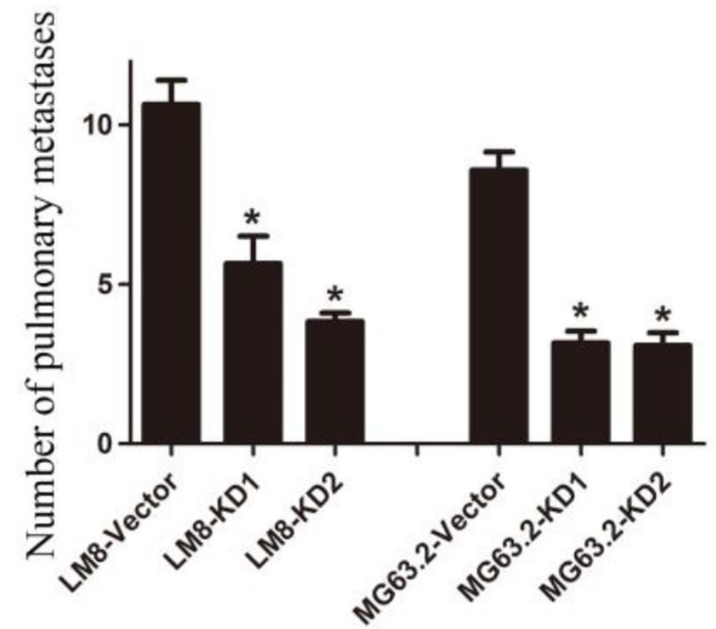

Figure 7: CD151 knockdown suppresses osteosarcoma pulmonary metastasis in vivo. A. Tumor weights at 30 days after tibial injection of LM8 (left) and MG63.2 (right) cells. B. Weight of the lungs at 30 days after tibial injection of LM8 cells (left) and MG63.2 cells (right). C. Representative photographs of pulmonary metastatic foci produced 30 days after tibial injection of LM8 cells (left) or MG63.2 cells (right). D. Representative HE analysis of lung metastases from mice injected with LM8 cells groups (top) or MG63.2 cells groups (bottom). Arrows indicate metastatic foci. E. Numbers of pulmonary metastatic foci. Quantitative data are represented as the mean and SD $(n=5)$. *indicates a statistically significant difference compared to the vector control (all $p<0.001)$. 
in patients with metastasis than patients without, which may be due to the small sample size. Larger patient cohort clearly suggested that CD151 expression correlates with poorer prognosis. We also analyzed the effect of CD151 over-expression in vivo, but observed no differences (data not shown), suggesting that baseline levels of CD151 may be sufficient to induce metastasis. Furthermore, CD151 silencing suppressed osteosarcoma metastasis without altering osteosarcoma cell viability or proliferation in vitro as well as LM8 or MG63.2 tumor morphology and growth in vivo. These results are consistent with a recent report by Zhang et al. [28] in which CD151 knockdown inhibits metastasis in one osteosarcoma cell line with continuous KRAS activation (143B). Similarly, in CD151 knockout mice, the number of metastatic lesions in the lung was about $25 \%$ of that observed in the control group although the area of metastatic lesions remained unchanged [2931]. Hence, CD151 most likely affects the later stages of osteosarcoma progression, in which cells invade into surrounding tissue and encounter the extracellular matrix. In addition, CD151 is regarded as a potential therapeutic target based on its role in promoting tumor progression, and several groups have proposed and developed antibody-based immunotherapies against CD151 [15] while others have reported soluble large-loop proteins or RNAi technology to inhibit CD151 [4, 32]. However, the clinical benefits of these therapeutic strategies have yet to be determined.

Consistent with the putative role of CD151 in human osteosarcoma metastasis, we observed that CD151 expression in osteosarcoma cells with high metastatic potential was significantly higher than that in cells with low metastatic potential. Furthermore, previous studies have shown that CD151 overexpression increased the migration and invasion of malignant cells, which was ameliorated with CD151 knockdown [24, 33, 34]. These findings were consistent with the present study in which CD151 silencing inhibited LM8 cell migration and Matrigel invasion as well as MG63.2 cell migration. Given that miR-152 was reported to target CD151 expression in gastric cancer, repressing gastric cancer cell proliferation and motility [35], further studies will evaluate the role of this particular microRNA in regulating CD151 expression in osteosarcoma.

The current understanding of tumor invasion is that there are two modes of tumor cell movement: one is the proteolysis-guided mesenchymal movement induced by Rho/ROCK, and the other is the actomyosin-driven amoeboid movement by proteases, particularly matrix metalloproteinases (MMPs) [36]. CD151-deficient cells exhibited decreased levels of the Rho family with integrins and small GTPase activation [6, 37], resulting in the decreased invasion and migration of tumor cells [36, 38]. Cell migration is also biphasic with respect to adhesion strength [38]. CD151 is known to support adhesion strengthening [29], which is consistent with the present study in which ablation of CD151 inhibited the stable cellcell attachments in LM8 and MG63.2 osteosarcoma cells. These findings suggest that CD151 silencing reduced the intercellular adhesion in a similar manner as that reported for breast cancer intercellular adhesion [8, 14, 23, 39, 40]. In addition, the adhesion of the osteosarcoma cells to the extracellular matrix was compromised upon CD151 silencing. Because elevated adhesion to neighboring cells and extracellular matrix may increase cellular migration and subsequently influence the invasion of malignant cells, the reduced metastasis observed with ablation of CD151 may be mediated through suppression of osteosarcoma cell adhesion.

CD151 interaction with extracellular matrix or intercellular junctions can alter the migration of malignant cells via altering cell signaling events [13] that results in the upregulation of enzymes involved in the degradation of extracellular matrix [29, 41]. Both PI3K-Akt and p38MAPK induce cellular migration and invasion, as well as capillary formation and intravascular permeability [21, 22]. In the present study, p38 and Akt phosphorylation was reduced significantly after CD151 silencing. However, further studies are required to determine if these signaling pathways mediated the reduction in metastatic potential observed with CD151 silencing.

CD151 may directly interact with $\alpha 3 \beta 1, \alpha 6 \beta 4, \alpha 6 \beta 1$ and $\beta 1$ integrins to alter the adhesion with adjacent cells and extracellular matrix [39, 42-45]. In B16BL6 murine melanoma cells, interaction of CD151 with $\alpha 3 \beta 1$ integrin was reduced with its glycosylation, subsequently altering cell migration and invasion [46]. Tyrosine phosphorylation of the non-receptor tyrosine kinase, FAK, in response to cell adhesion represents an early event in integrin signaling [47]. FAK, which alters the PI3K/Akt, MAPK/p38, and phospholipase $C$ pathways [41, 47-51], is essential for cell migration and plays an important role in tumor metastasis $[48,52]$. In the present study, the protein levels of integrin $\beta 1$ and FAK were reduced significantly following CD151 silencing. The reduced integrin $\beta 1$ and FAK protein levels with CD151 silencing may have resulted in the altered phosphorylation of Akt and p38 and subsequent reduction in cell adhesion and metastasis; however, further studies are required to determine the effects were mediated by additional pathways. In addition, the spheroid size was reduced following CD151 knockdown after $24 \mathrm{~h}$ which was accompanied with decreased cell attachment. This is consistent with a previous study, which reported that CD151 alters $\alpha 6 \beta 1$ integrin adhesion strengthening [50].

Taken together, CD151 promotes the migration, invasion, and metastasis of osteosarcoma by altering adhesion, suggesting that it may prove to be a critical diagnostic and/or prognostic marker as well as therapeutic target. However, the specific molecular mechanism underlying the regulatory role of CD151 in the metastasis of osteosarcoma and the efficacy of therapy targeting CD151 remain to be elucidated in further studies. 


\section{MATERIALS AND METHODS}

\section{CD151 expression by immunohistochemical (IHC) staining on tissue microarrays}

TMA-1 contains samples from patients treated in Shanghai General Hospital. TMA-2 contains samples from patients treated in Massachusetts General Hospital, Boston. All patient samples and clinical data in this study were retrieved after patient consent and Institutional Review Board (IRB) approval from each institution were obtained. IHC analyses of a tumor tissue array (TMA) and human osteosarcoma tumor tissues were conducted essentially as described previously [16]. In brief, antigens were retrieved using a decloaking chamber in the presence of 0.01M EDTA buffer (pH 9.0). After blocking in goat serum, TMA slides were incubated with a CD151-specific monoclonal antibody (Life Span BioSciences, Seattle, WA, USA) followed by incubation with a biotinylated secondary antibody. The reaction was developed using a DAB Kit (BD Bioscience, Franklin Lakes, NJ, USA), and the tissues were counterstained with hematoxylin. The immunoreactive score (IRS) was evaluated on the basis of staining intensity and the percentages of positively stained areas by three independent staff members as previously described [53]. The proportion of immunopositive tumor cells was evaluated. The intensity of immunostaining was evaluated by using four scores as follows: strong immunopositivity of the tumor cells in low-power view $(\times 40), 3+$; weak immunopositivity in low-power view but obvious staining in high-power view $(\times 400), 1+$; median intensity between $1+$ and $3+, 2+$; and absence of immunostaining, 0 . The percentage of immunopositive tumor cells is also evaluated and scored as $0(<5 \%), 1(5-$ $25 \%), 2(25-50 \%), 3(50-75 \%), 4(75-95 \%)$. Final scored was multiplied by immune-intensity score and immunepercentage score.

\section{Cell lines and culture}

The murine LM8 osteosarcoma cell line with high metastatic potential and its parental cell line Dunn with low metastatic potential were originally established by Prof. Tatsuya Asai (Department of Orthopaedic Surgery, Osaka Medical Center for Cancer and Cardiovascular Diseases, Osaka, Japan). The human MG63.2 osteosarcoma cell line with high metastatic potential was previously established and characterized [20,54], and the MG63 human osteosarcoma line with low metastatic potential was purchased from ATCC (Manassas, VA, USA). DNA fingerprinting was performed to rule out cell culture contamination. All cells were cultured in high glucose Dulbecco's Modified Eagle's Medium (DMEM-h) supplemented with $10 \%$ fetal bovine serum, $100 \mathrm{U} /$ $\mathrm{mL}$ penicillin, and $100 \mu \mathrm{g} / \mathrm{mL}$ streptomycin (all from Invitrogen, Carlsbad, CA, USA) in a humidified incubator at $37^{\circ} \mathrm{C}$ in $5 \% \mathrm{CO}_{2}$. Cells in logarithmic growth phase were harvested and used in the following experiments.

\section{Preparation of LM8 and MG63.2 osteosarcoma cells with stable expression of CD151 short- hairpin RNA (shRNA)}

The specific shRNA sequences targeting CD151 were determined according to the WI siRNA Selection Program (http://sirna.wi.mit.edu/). For each cell line, the following two candidate sequences for siRNA knockdown of CD151 were selected: LM8 cells, gaacetgttacgcttgtactt (KD1) and cagctgctgtaagactatggt (KD2); MG63.2 cells, gcctcaagtacctgctgttta (KD1) and gagaccatgcctccaacatct (KD2). DNA sequences that expressed the above siRNA sequences and contained the appropriate restriction enzyme cleavage sites were synthesized for the construction of a lentivirus expressing CD151 shRNA. Subsequently, this lentivirus was transfected into 293T cells in the presence of plasmids, followed by lentivirus packaging. The supernatant was harvested after $48 \mathrm{~h}$ and filtered through a $0.45-\mu \mathrm{m}$ filter. LM8 and MG63.2 osteosarcoma cell were transduced with lentiviral vectors expressing each shRNA sequence targeting the CD151 transcript (KD1 and KD2) or with empty lentiviral vectors (vector control). Cells with stable expression of CD151 shRNA or empty lentiviral vector were screened with 2 $\mu \mathrm{g} / \mathrm{mL}$ puromycin.

\section{Western blot assay}

Cells were harvested, washed twice with PBS, and lysed with RIPA Lysis Buffer (Beyotime Institute of Biotechnology, Shanghai, China) with protease inhibitors (Thermo Fisher Scientific). Tumor tissues retrieved from $-80^{\circ} \mathrm{C}$ storage were rapidly immersed in liquid nitrogen followed by lysis with RIPA Lysis Buffer and protease inhibitors. Protein concentrations were determined with a Pierce BCA Protein Assay Kit (Thermo Fisher Scientific). Total protein $(50 \mu \mathrm{g} / \mathrm{lane})$ was separated by $10 \%$ SDSPAGE and was transferred to nitrocellulose membranes. After blocking for 60 min with 5\% milk solutions prepared in PBS, the membranes were incubated overnight at $4{ }^{\circ} \mathrm{C}$ with 1:1000 dilutions of the following primary antibodies: CD151 (\#5901), FAK (\#2146-1), and CD29 (\#1798-1; all from abcam, Cambridge, UK), Akt (\#4685), p-Akt (\#4060), p38 (\#8690), p-p38 (\#4511), mTOR (\#5536), p70S6 (\#9208), p65 (\#8242), and p-p65 (\#3033; all from Cell Signaling Technology, Danvers, MA, USA). After the membranes were washed, they were incubated for $1 \mathrm{~h}$ with the appropriate peroxidase-conjugated secondary antibody (1:1000 dilution). Membranes were developed using the Odyssey Two-Color Infrared Laser Imaging System (LI-COR Biosciences, Lincoln, NB, USA). The signal generated by actin (\#4973; Cell Signaling Technology) was used as an internal control. 


\section{Detection of cell cycle and apoptosis by flow cytometry}

Osteosarcoma cells were seeded into 6-well plates $\left(3 \times 10^{5}\right.$ cells $/$ well $)$ and incubated in a humidified environment of $5 \% \mathrm{CO}_{2}$ at $37^{\circ} \mathrm{C}$ for $24 \mathrm{~h}$. To determine cell cycle progression, cells were harvested, washed in PBS twice, incubated in $300 \mu \mathrm{L}$ of $1 \times$ binding buffer with propidium iodide (PI, Sigma, St. Louis, MO, USA), NP40, and RNase A (BD Biosciences, San Jose, CA, USA) at room temperature for $15 \mathrm{~min}$. To evaluate apoptosis, the cells were incubated in $100 \mu \mathrm{L}$ of $1 \times$ binding buffer with annexin-V/PI double staining solution (BD Biosciences) at room temperature for $15 \mathrm{~min}$. The stained cells were analyzed by flow cytometry. The proportion of cells in the different stages of the cell cycle or those that were apoptotic or necrotic were calculated using Mod-Fit LT software (Verity Software House).

\section{Detection of cell viability}

Cells $\left(3 \times 10^{3}\right.$ cells/well $)$ were seeded into 96-well plates and cultured overnight. After 24 or $72 \mathrm{~h}, 20 \mu \mathrm{L}$ of MTT (5 mg/mL, Sigma) was added into each well for another $4 \mathrm{~h}$. The supernatant was removed, and $150 \mu \mathrm{L}$ of DMSO was added into each well. The absorbance was then measured using a model ELX800 Micro Plate Reader (Bio-Tec Instruments, Winooski, VT, USA) at $490 \mathrm{~nm}$.

\section{Detection of CD151 surface expression by flow cytometry analysis}

Osteosarcoma cells were seeded into plates $\left(8 \times 10^{5}\right.$ cells/well) and incubated in a humidified environment of $5 \% \mathrm{CO}_{2}$ at $37^{\circ} \mathrm{C}$. After $24 \mathrm{~h}$, cells were harvested and washed twice in PBS. The cell suspensions $\left(1 \times 10^{6}\right.$ cells $/ 40 \mu \mathrm{l}$ ) were incubated with $10 \mu \mathrm{L}$ of CD151-PE (R\&D, Minneapolis, MN, USA) in the dark at $2-8^{\circ} \mathrm{C}$ for $45 \mathrm{~min}$. Following washing in PBS twice, $500 \mu \mathrm{L}$ of PBS was added to prepare single cell suspensions, and flow cytometry analysis was performed using a BD-FACS Calibur (BD Biosciences).

\section{Analysis of cell-cell attachment}

Poly-2-hydroxyethyl acrylate (Sigma) was added to 6-well plates $(1 \mathrm{~mL} /$ well $)$, which were air-dried. The osteosarcoma cells were seeded into plates $\left(3 \times 10^{5}\right.$ cells/ well) and incubated in a humidified environment of $5 \% \mathrm{CO}_{2}$ at $37^{\circ} \mathrm{C}$. Adherent cells were characterized by spherical growth in three-dimensional (3D) 6-well culture plates. Cell-cell attachments were photographed at 0, 24, 48 and $72 \mathrm{~h}$ using a phase-contrast microscope. Cellcell attachments, which were presented as the average spheroid size $\left(1 \times 10^{3} \mathrm{~m}^{2}\right)=$ the area/number of spheroid, in multiple random fields were quantified using Nikon NIS-Elements Advanced Analysis Software.

\section{Detection of cell adhesion}

Matrigel $(20 \mu \mathrm{L} /$ well, BD Biosciences) and 10 $\mathrm{mg} / \mathrm{mL}$ BSA $(20 \mu \mathrm{L} /$ well, Sangon Biotech, Shanghai, China) were added to 96-well plates, followed by incubation at $37^{\circ} \mathrm{C}$ for $0.5-1 \mathrm{~h}$. Cells were seeded into 96 -well plates $\left(1 \times 10^{4} /\right.$ well $)$ and incubated at $37^{\circ} \mathrm{C}$ for $45 \mathrm{~min}$. The suspended cells were removed, and the adherent cells were washed in PBS twice and fixed in $95 \%$ ethanol at room temperature for $10 \mathrm{~min}$. Cells were air-dried and stained with crystal violet for $20 \mathrm{~min}$. After the cells were washed and air-dried, 33\% glacial acetic acid (Sangon Biotech, Shanghai, China) was used to dissolve the crystal violet, and optical density (OD) was measured at $595 \mathrm{~nm}$. The cell adhesion rate was calculated as follows: cell adhesion rate $=\left(\mathrm{OD}_{\text {Experiment }}\right.$ group $\left.-\mathrm{OD}_{\mathrm{BSA} \text { group }}\right) / \mathrm{OD}_{\mathrm{BSA} \text { group }}$.

\section{Detection of cell migration}

Cells were seeded into 6 -well plates $\left(2 \times 10^{5}\right.$ cells/ well). After $24 \mathrm{~h}$, a scratch was made in the monolayer using a pipette, and the cells were washed twice in PBS. The cells were maintained in essential medium containing $2 \%$ FBS and were photographed at 0,24 and $48 \mathrm{~h}$ to observe the cell migration. The cell migration rate was calculated as follows: cell migration rate $=$ wound area at $0 \mathrm{~h} /$ wound area at a specific time point.

\section{Transwell invasion assay}

Matrigel was added $(50 \mu \mathrm{L} /$ well $)$ to the upper chambers of a Transwell followed by incubation at $37^{\circ} \mathrm{C}$. After $30 \mathrm{~min}$, the cells were seeded at $5 \times 10^{4}$ cells $/$ well. Medium containing 2\% FBS was added to the upper chambers, and medium containing $10 \%$ FBS was added to the lower chambers, and the plates were incubated at $37^{\circ} \mathrm{C}$ for $24 \mathrm{~h}$. Cells in the upper chambers were removed, and lower chambers were washed in PBS twice, fixed in 95\% ethanol, air-dried and stained with crystal violet. Cells were photographed, and the number of cells in the lower chambers was determined.

\section{Animal experiments}

$\mathrm{C} 3 \mathrm{H}$ mice (inoculated with LM8 cells) and nude mice (inoculated with MG63.2 cells) aged 4 weeks were purchased from the Shanghai SLAC Experimental Animal Center (Shanghai, China). Mice were housed in a standard animal laboratory with free access to water and food. They were kept under constant environmental conditions with a 12-h light-dark cycle. All operations were performed under aseptic conditions. All the animal-related procedures were approved by the Institutional Animal Care and Use Committee (IACUC) of Shanghai, General People's Hospital of Shanghai. 


\section{Mice tibial tumor models and pulmonary metastasis models}

After the LM8 and MG63.2 cells were washed with cold PBS, they were suspended in cold PBS at a final concentration of $1 \times 10^{8}$ cells $/ \mathrm{mL}$. LM8 cells $(10 \mu \mathrm{L})$ were injected into the tibia of $\mathrm{C} 3 \mathrm{H}$ mice, and MG63.2 cells $(10 \mu \mathrm{L})$ were injected into the tibia of nude mice. Specifically, the cell suspensions were injected into the medullary cavities of the tibia. Mice were divided into the following three groups (10 mice per group): vector control group, KD1 group and KD2 group. All of the mice were euthanized at once the first mouse died. The lungs and legs were collected, fixed, embedded and sectioned for hematoxylin and eosin (HE) staining or IHC analysis. Histological examination and counting of the metastatic lesions were performed. Lungs containing metastases were immersed in Bouin solution to distinguish white tumor colonies from yellowish lung parenchyma. Metastasis was measured by visually counting the number of lesions in the entire mouse lung section for each mouse using Nikon NIS-Elements software (Nikon Corporation Instruments, Tokyo, Japan) at 10X magnification.

\section{Statistical analysis}

The IRS for the 39 human osteosarcoma tissues had non-normal distribution and, thus, was expressed as median and inter-quartile range (IQR). The non-parametric Mann-Whitney test was performed to compare differences in IRS between patients with and without metastasis. Other continuous data were expressed as mean \pm standard deviation (SD). One-way analysis of variance (ANOVA) was performed to compare the differences between groups; post-hoc tests with Bonferroni correction were performed to compare the pair-wise groups. For survival rates, Kaplan-Meier curves with log-rank tests were performed to investigate the differences of survival rate between patients with low (1-8.9) and high (9-12) CD151 levels. $P<0.05$ was considered statistically significant. All experiments were repeated three times. The statistical analysis was performed using GraphPad Prism 5.0 (La Jolla, CA, USA).

\section{CONFLICTS OF INTEREST}

The authors declare no conflicts of interest.

\section{GRANT SUPPORT}

This work was supported by NSFC (81202115), a Research Grant from Shanghai Hospital Development Center (SHDC12013107) and the Excellent Young Talent Program of Shanghai Municipal Commission of Health and Family Planning (XYQ2013108). IL27-A driver of skin carcinogenesis (National Natural Science
Foundation of China, No. 81450110092), leading talents for Shanghai (Shanghai Municipal Human Resources and Social Security Bureau, 0403N14001), The research and application of Photodynamic induced Immunotherapy of Synovial sarcoma (Shanghai Charity Cancer Research Center, 0703N14012), The Construction of Osteoblast Specific Wwox Gene Knockout Spontaneous Osteosarcoma Model In Mice (Science and Technology Commission of Shanghai, 14140904000).

\section{REFERENCES}

1. Chou AJ, Geller DS, Gorlick R. Therapy for osteosarcoma: where do we go from here? Paediatr Drugs. 2008; 10:315-327.

2. Joo MW, Shin SH, Kang YK, Kawai A, Kim HS, Asavamongkolkul A, Jeon DG, Kim JD, Niu X, Tsuchiya H, Puri A, Wang EH, Chung SH, Chung YG. Osteosarcoma in Asian Populations Over the Age of 40 Years: A Multicenter Study. Ann Surg Oncol. 2015; 22:3557-3564.

3. Detchokul S, Williams ED, Parker MW, Frauman AG. Tetraspanins as regulators of the tumour microenvironment: implications for metastasis and therapeutic strategies. Br J Pharmacol. 2014; 171:5462-5490.

4. Kumari S, Devi Gt, Badana A, Dasari VR, Malla RR. CD151-A Striking Marker for Cancer Therapy. Biomark Cancer. 2015; 7:7-11.

5. Ang J, Fang BL, Ashman LK, Frauman AG. The migration and invasion of human prostate cancer cell lines involves CD151 expression. Oncol Rep. 2010; 24:1593-1597.

6. Hong IK, Jeoung DI, Ha KS, Kim YM, Lee H. Tetraspanin CD151 stimulates adhesion-dependent activation of Ras, $\mathrm{Rac}$, and $\mathrm{Cdc} 42$ by facilitating molecular association between betal integrins and small GTPases. J Biol Chem. 2012; 287:32027-32039.

7. Hong IK, Jin YJ, Byun HJ, Jeoung DI, Kim YM, Lee H. Homophilic interactions of Tetraspanin CD151 up-regulate motility and matrix metalloproteinase- 9 expression of human melanoma cells through adhesion-dependent c-Jun activation signaling pathways. J Biol Chem. 2006; 281:24279-24292.

8. Klosek SK, Nakashiro K, Hara S, Goda H, Hasegawa H, Hamakawa H. CD151 regulates HGF-stimulated morphogenesis of human breast cancer cells. Biochem Biophys Res Commun. 2009; 379:1097-1100.

9. Richardson MM, Jennings LK, Zhang XA. Tetraspanins and tumor progression. Clin Exp Metastasis. 2011; 28:261-270.

10. Zoller M. Tetraspanins: push and pull in suppressing and promoting metastasis. Nature Rev Cancer. 2009; 9:40-55.

11. Palmer TD, Martinez CH, Vasquez C, Hebron KE, JonesParis C, Arnold SA, Chan SM, Chalasani V, GomezLemus JA, Williams AK, Chin JL, Giannico GA, Ketova $\mathrm{T}$, et al. Integrin-free tetraspanin CD151 can inhibit tumor 
cell motility upon clustering and is a clinical indicator of prostate cancer progression. Cancer Res. 2014; 74:173-187.

12. Detchokul S, Newell B, Williams ED, Frauman AG. CD151 is associated with prostate cancer cell invasion and lymphangiogenesis in vivo. Oncol Rep. 2014; 31:241-247.

13. Sadej R, Grudowska A, Turczyk L, Kordek R, Romanska HM. CD151 in cancer progression and metastasis: a complex scenario. Lab Invest. 2014; 94:41-51.

14. Hasegawa M, Furuya M, Kasuya Y, Nishiyama M, Sugiura T, Nikaido T, Momota Y, Ichinose M, Kimura S. CD151 dynamics in carcinoma-stroma interaction: integrin expression, adhesion strength and proteolytic activity. Lab Invest. 2007; 87:882-892.

15. Haeuw JF, Goetsch L, Bailly C, Corvaia N. Tetraspanin CD151 as a target for antibody-based cancer immunotherapy. Biochem Soc Trans. 2011; 39:553-558.

16. Zijlstra A, Lewis J, Degryse B, Stuhlmann H, Quigley JP. The inhibition of tumor cell intravasation and subsequent metastasis via regulation of in vivo tumor cell motility by the tetraspanin CD151. Cancer Cell. 2008; 13:221-234.

17. Kohno M, Hasegawa H, Miyake M, Yamamoto T, Fujita S. CD151 enhances cell motility and metastasis of cancer cells in the presence of focal adhesion kinase. Int J Cancer. 2002; 97:336-343.

18. Zhang Z, Zhang L, Hua Y, Jia X, Li J, Hu S, Peng X, Yang P, Sun M, Ma F, Cai Z. Comparative proteomic analysis of plasma membrane proteins between human osteosarcoma and normal osteoblastic cell lines. BMC Cancer. 2010; 10:206.

19. Mohseny AB, Hogendoorn PC, Cleton-Jansen AM. Osteosarcoma models: from cell lines to zebrafish. Sarcoma. 2012; 2012:417271.

20. Su Y, Luo X, He BC, Wang Y, Chen L, Zuo GW, Liu B, Bi Y, Huang J, Zhu GH, He Y, Kang Q, Luo J, Shen J, Chen $\mathrm{J}$, Jin $\mathrm{X}$, et al. Establishment and characterization of a new highly metastatic human osteosarcoma cell line. Clin Exp Metastasis. 2009; 26:599-610.

21. Chin YR, Toker A. Function of Akt/PKB signaling to cell motility, invasion and the tumor stroma in cancer. Cell Signal. 2009; 21:470-476.

22. Grossi V, Peserico A, Tezil T, Simone C. p38alpha MAPK pathway: a key factor in colorectal cancer therapy and chemoresistance. World J Gastroenterol. 2014; 20:9744-9758.

23. Yang XH, Richardson AL, Torres-Arzayus MI, Zhou P, Sharma C, Kazarov AR, Andzelm MM, Strominger JL, Brown M, Hemler ME. CD151 accelerates breast cancer by regulating alpha 6 integrin function, signaling, and molecular organization. Cancer Res. 2008; 68:3204-3213.

24. Kwon MJ, Park S, Choi JY, Oh E, Kim YJ, Park YH, Cho EY, Kwon MJ, Nam SJ, Im YH, Shin YK, Choi YL. Clinical significance of CD151 overexpression in subtypes of invasive breast cancer. Br J Cancer. 2012; 106:923-930.

25. Yang XH, Flores LM, Li Q, Zhou P, Xu F, Krop IE, Hemler ME. Disruption of laminin-integrin-CD151-focal adhesion kinase axis sensitizes breast cancer cells to ErbB2 antagonists. Cancer Res. 2010; 70:2256-2263.

26. Ang J LM, Ashman LK, Kan K, Frauman AG. CD151 protein expression predicts the clinical outcome of lowgrade primary prostate cancer better than histologic grading: a new prognostic indicator? Cancer Epidemiol Biomarkers Prev. 2004; 13:1717-1721.

27. Takahiro Tokuhara HH, Noboru Hattori, Hisao Ishida, Toshihiko Taki, Shuuichi Tachibana, Sinjiroh Sasaki, Masayuki Miyake. Clinical significance of CD151 gene expression in non-small cell lung cancer. Clin Cancer Res. 2001; 7:4109-4114.

28. Zhang Z, Wang F, Li Q, Zhang H, Cui Y, Ma C, Zhu J, Gu X, Sun Z. CD151 knockdown inhibits osteosarcoma metastasis through the GSK-3 $\beta / \beta$-catenin/MMP9 pathway. Oncol Rep. 2016; 35:1764-1770.

29. Yoshito Takeda ARK, Catherine E. Butterfield, Benjamin D. Hopkins, Laura E. Deletion of tetraspanin Cd151 results in decreased pathologic angiogenesis in vivo and in vitro. Blood. 2007; 109:1524-1532.

30. Deng X, Li Q, Hoff J, Novak M, Yang H, Jin H, Erfani SF, Sharma C, Zhou P, Rabinovitz I, Sonnenberg A, Yi Y, Zhou $\mathrm{P}$, et al. Integrin-Associated CD151 Drives ErbB2-Evoked Mammary Tumor Onset and Metastasis. Neoplasia. 2012; 14:678-673.

31. Takeda Y, Li Q, Kazarov AR, Epardaud M, Elpek K, Turley SJ, Hemler ME. Diminished metastasis in tetraspanin CD151-knockout mice. Blood. 2011; 118:464-472.

32. Hemler ME. Targeting of tetraspanin proteins-potential benefits and strategies. Nat Rev Drug Discov. 2008; 7:747-758.

33. Ke AW, Shi GM, Zhou J, Wu FZ, Ding ZB, Hu MY, Xu Y, Song ZJ, Wang ZJ, Wu JC, Bai DS, Li JC, Liu KD, et al. Role of overexpression of CD151 and/or c-Met in predicting prognosis of hepatocellular carcinoma. Hepatology. 2009; 49:491-503.

34. Shi GM, Ke AW, Zhou J, Wang XY, Xu Y, Ding ZB, Devbhandari RP, Huang XY, Qiu SJ, Shi YH, Dai Z, Yang XR, Yang GH, et al. CD151 modulates expression of matrix metalloproteinase 9 and promotes neoangiogenesis and progression of hepatocellular carcinoma. Hepatology. 2010; 52:183-196.

35. Zhai R, Kan X, Wang B, Du H, Long Y, Wu H, Tao K, Wang G, Bao L, Li F, Zhang W. miR-152 suppresses gastric cancer cell proliferation and motility by targeting CD151. Tumour Biol. 2014; 35:11367-11373.

36. Narumiya S, Tanji M, Ishizaki T. Rho signaling, ROCK and mDia1, in transformation, metastasis and invasion. Cancer Metastasis Rev. 2009; 28:65-76.

37. Novitskaya V, Romanska H, Kordek R, Potemski P, Kusinska R, Parsons M, Odintsova E, Berditchevski F. Integrin alpha 3 beta 1-CD151 complex regulates dimerization of ErbB2 via RhoA. Oncogene. 2014; 33:2779-2789. 
38. Haeger A, Wolf K, Zegers MM, Friedl P. Collective cell migration: guidance principles and hierarchies. Trends Cell Biol. 2015; 25:556-566.

39. Yang XH, Mirchev R, Deng X, Yacono P, Yang HL, Golan DE, Hemler ME. CD151 restricts the alpha6 integrin diffusion mode. J Cell Sci. 2012; 125:1478-1487.

40. Chien CW, Lin SC, Lai YY, Lin BW, Lin SC, Lee JC, Tsai SJ. Regulation of CD151 by hypoxia controls cell adhesion and metastasis in colorectal cancer. Clin Cancer Res. 2008; 14:8043-8051.

41. Franco M, Muratori C, Corso S, Tenaglia E, Bertotti A, Capparuccia L, Trusolino L, Comoglio PM, Tamagnone L. The tetraspanin CD151 is required for Met-dependent signaling and tumor cell growth. J Biol Chem. 2010; 285:38756-38764.

42. Nishiuchi R, Sanzen N, Nada S, Sumida Y, Wada Y, Okada M, Takagi J, Hasegawa H, Sekiguchi K. Potentiation of the ligand-binding activity of integrin alpha3beta1 via association with tetraspanin CD151. Proc Natl Acad Sci U S A. 2005; 102:1939-1944.

43. Johnson JL, Winterwood N, DeMali KA, Stipp CS. Tetraspanin CD151 regulates RhoA activation and the dynamic stability of carcinoma cell-cell contacts. J Cell Sci. 2009; 122:2263-2273.

44. Novitskaya V, Romanska H, Dawoud M, Jones JL, Berditchevski F. Tetraspanin CD151 regulates growth of mammary epithelial cells in three-dimensional extracellular matrix: implication for mammary ductal carcinoma in situ. Cancer Res. 2010; 70:4698-4708.

45. Wolfenson H, Lavelin I, Geiger B. Dynamic regulation of the structure and functions of integrin adhesions. Developmental Cell. 2013; 24:447-458.
46. Ranjan A, Bane SM, Kalraiya RD. Glycosylation of the laminin receptor $(\alpha 3 \beta 1)$ regulates its association with tetraspanin CD151: Impact on cell spreading, motility, degradation and invasion of basement membrane by tumor cells. Exp Cell Res. 2014; 322:249-364.

47. Byron A, Morgan MR, Humphries MJ. Adhesion signalling complexes. Current Biol. 2010; 20:R1063-1067.

48. Zhang J, Hochwald SN. The role of FAK in tumor metabolism and therapy. Pharmacol Ther. 2014; 142:154-163.

49. Lee BY, Timpson P, Horvath LG, Daly RJ. FAK signaling in human cancer as a target for therapeutics. Pharmacol Ther. 2015; 146:132-149.

50. Lammerding J, Kazarov AR, Huang H, Lee RT, Hemler ME. Tetraspanin CD151 regulates alpha6beta1 integrin adhesion strengthening. Proc Natl Acad Sci U S A. 2003; 100:7616-7621.

51. Linder S, Aepfelbacher M. Podosomes: adhesion hot-spots of invasive cells. Trends Cell Biol. 2003; 13:376-385.

52. Ritt M, Guan JL, Sivaramakrishnan S. Visualizing and manipulating focal adhesion kinase regulation in live cells. J Biol Chem. 2013; 288:8875-8886.

53. Remmele W, Stegner HE. Recommendation for uniform definition of an immunoreactive score (IRS) for immunohistochemical estrogen receptor detection (ER-ICA) in breast cancer tissue. Pathologe. 1987; 8:138-140.

54. Yue S, Mu W, Zoller M. Tspan8 and CD151 promote metastasis by distinct mechanisms. Eur J Cancer. 2013; 49:2934-2948. 